\title{
Organisational Resilience: understanding and identifying the essential concepts
}

\author{
B. M. Braes \& D. J. Brooks \\ School of Computer \& Security Science, Edith Cowan University, \\ Western Australia
}

\begin{abstract}
Increasing political turmoil across many regions has increased concerns amongst business, social and governmental circles over the ability of organisations to anticipate and respond positively to disruptions. Organisations are spending increased sums of money to raise levels of governance and security protocols, under the term resilience. Nevertheless, term organisational resilience is vague, and the term itself implies multi-disciplined and diverse strategies and tactics, requiring a diversity of skills and knowledge that reaches beyond security and governance alone. The resilience domain is still developing; however, early embodiments of organisational resilience, originating in the United Kingdom and the United States, appear to be rebranding of business continuity management strategies, put together as a 'resilience processes' or 'resilience systems'.

More recently 'resilience management systems', claiming to deliver benefits akin to those that the International Standards Organisation 9001 gave the Quality Assurance discipline have begun to appear. Nevertheless, there is a constant absence of a clearly defined and researched set of essential concepts that make up the theoretical structure of Organisational Resilience. It is argued that Organisational Resilience is both a top-down culture (value, leadership) and bottom-up, delivered by a number of functional processes such as risk management, governance, interdependencies, security management, situational awareness and business continuity. However, validation of these elements is required and is currently underway.
\end{abstract}

Keywords: resilience, organisational, expertise, practitioner, essential, concepts, standards, security, business, continuity, emergency, crisis, recovery. 


\section{Introduction}

Within the Australian context, resilience is referred to extensively in many elements of national security, critical infrastructure and corporate security environment discourse. The Australian Government's National Security Science and Innovation Strategy document clearly details the need to build a more prepared and resilient society [1]. In addition, the National Security Resilience Policy Division (NSRPD) provides policy advice on emergency management, protective security, identity security, e-security and critical infrastructure protection [1]. Nevertheless, resilience is an undefined term when considered within the context of organisations.

There is a need to extract, understand and identify the essential concepts of Organisational Resilience [2], in particular, resilience enablers and processes currently used across various sectors, organisations and localities. The development of a United States Standard [3] and the decision of United Kingdom Government to base its National Civil Contingency Planning framework on the concept of resilience [4,5] raises the desire to better understand resilience in an organisational context.

The continued occurrence of major natural disasters across many parts of the world and the catastrophic affects these disasters have upon organisations is driving such research to promote Organisational Resilience as a key strategic goal amongst organisations' in the future. Recent events in Christchurch, New Zealand and Queensland, Australia, have highlighted the need for organisations' to increase their resilience in order to maintain the capacity to achieve their objectives. Organisations' must be able to adapt if they are to survive [6].

\section{Background}

The globalised nature of the modern world including markets, cultures, organisations and strategic threats has led to organisations facing threats that are frequently not identified or recognised until they rapidly escalate into a crisis or catastrophic event. Recent research indicates that the frequency and severity of disruptive events is growing [7]. Emerging out of this evolving global landscape is the relatively new concept of Organisational Resilience.

The term resilience has been used with increasing popularity across many disciplines including health, medicine, information management and economics. For example in the field of psychology, resilience is a well researched phenomenon with such understanding that resiliency and resilience are two different constructs. Resiliency relates to a personality characteristic and resilience refers to a dynamic developmental process [8]. However, resilience is liberally used in organisations and across society in numerous contexts. There is little consistency in its use in terms of Organisational Resilience and a lack of common understanding as to the essential concepts prevails. The fields of enterprise risk management, business continuity management, emergency management, crisis management, physical security and cyber-security have been at the heart of organisations' attempts to protect themselves in the past. 
Following the World Trade Centre attacks of September 2001, the London bombings of 2007, the Bali bombings of 2002 and 2005, and the Mumbai attacks of 2008, organisations across the globe have rightly increased their efforts to protect themselves with vigour. Resilience handbooks and manuals have appeared across the world published by consultancy firms and governments alike, these are augmented by an increasing array of standards, either published or under development including national standards in the U.S.A [3]; Denmark [9] and The Netherlands [10], a national standard in the process of development and review in Australia and an International Standards Organisation Standard [11] in the drafting and consultation stage.

These publications provide evidence of the growth in the awareness of the concept of organisational resilience. They are augmented by governmental adoption of the resilience initiative. As previously mentioned the Australia government has built its disaster management and response policy upon the concept of resilience, with the establishment in 2009 of the Natural Disaster Resilience Program (NDRP) [12] as well as championing resilience strategies in the critical infrastructure domain [13]. In the United Kingdom, the contribution of the defence forces is the subject of major policy document [14].

\section{Study objectives}

The objectives of this study were to consider:

1. What are the essential concepts that contribute to making an organisation resilient?

2. What is Organisational Resilience; a management philosophy or rather the outcome of numerous management processes?

\section{Study design}

The study currently underway is a four-phased Grounded Theory study (Figure 1) designed to extract, tabulate and validate the essential concepts of organisational resilience.

Phase One of the study entailed the analysis of a number of Organisational Resilience Standards published and sanctioned in the United States [3], The Netherlands [10] and Denmark [9] The review of standards has been selected as standards present a consensual opinion as to the best manner to deal with a subject. The phase aimed to develop a list of concepts that contribute to Organisational Resilience using linguistic analysis of the standards. Various government documents from the United Kingdom [4, 5] and Australia [1, 13] outlining policy involving resilience have also been analysed. The list of common elements from these documents has been extracted and tabulated. A panel of five experts, one expert from Australia, USA, UK, Singapore and Hong Kong representing the each of the regions covered by the study for validated the elements. As Organisational Resilience is such a diverse and multidimensional philosophy that is currently undefined and unstructured, it will not 
be possible to use a statistically representative population and as such, convenience sampling is adopted in the study.

Phase Two comprises semi-structured interviews with a second group of five experts to identify the hierarchy of significance of the concepts identified in Phase One. The resultant data gleaned from the interviews will be presented to a further ten experts using the Delphi method. This approach consists of a survey conducted in two or more rounds and provides the participants an anonymous summary of the experts' forecasts from the previous round, as well as the reasons they provided for their judgments. Experts in the second round can alter the original assessments if they want to or stick to their previous opinion. It is held that during this process the range of the responses will decrease and the group of experts will converge towards the 'correct' answer [15].

Phase Three comprises a survey of industry practitioners conducted across a wide range of organisation types in an effort to gain validation of the table of essential concepts developed in Phases One and Two. The generation of data sets through document analysis, semi-structured interviews and surveys support the Grounded Theory doctrine of assembly data from multiple sources to create a rich data set for analysis [16].

Finaly, Phase Four will be a comparative study of the data outputs of Phases Two and Three, with the aim of this phase to not only to gather facts but to also point out where the outcomes of the study can produce improvement.

\section{Underlying theory}

The study was supported by the theory of cognitive psychology, using the declarative memory approach within long-term memory and the formation of concepts. The human brain gathers inputs through sensory inactions. Dependent on the need to retain such data, this data may be transmitted into the short-term memory or discarded if not required. Short-term memory has a low capacity and weakness for storage, and Miller (cited in [17]) claimed that in terms of capacity short-term memory may only store seven plus or minus two units, with a unit comprising of numbers, letters, words [18] or labels. According to Eysenck and Keane [19], there are noteworthy differentials between short-term memory and long-term memory, such as sequential duration, storage capacity, forgetting mechanism and the effects of brain damage. Long-term memory is said to be the most important component for knowledge development and maintenance.

Episodic memory, which is the storage and encoding of memory gained through day to day experiences, is promoted as being of a higher cognitive level [19]. Whereas semantic memory, which is similar to episodic memory, acts like a mental thesaurus that organises the knowledge that a person possesses, and which collectively make up declarative memory [20]; however, all have an important impact upon concepts. The study used the declarative memory approach as this underpins the utilisation of experts in the data validation process. 


\section{Concepts}

Concepts are a vital part of everyday life, as they are continuously contributing to our perceptions, learning, memory and language [21]. The question of the source of our first concepts is often asked. The response is that they are gained between birth and three years, when we begin to recognise uniformity in our environment and start to identify language labels or symbols for these regularities [22]. The learning process in early years is to some degree a process of discovery, where patterns and uniformity in events are recognised; when later in life this process is heavily influenced by words or symbols.

Concepts are pictures developed in the mind that characterise classes of objects and other things. Concepts differ from categories in that number categories grouped together make up a concept. Such differentiation is often confused and difficult to maintain due to the two being inextricably linked [19]. Concepts are the cement that bond together our mental being, they link our past experiences with what we are doing today because they are interlinked with all our knowledge structures [23]. Concepts are organised into hierarchies, which all contain three categories, super-ordinate at the top, basic-level in the middle and sub-ordinate at the bottom. An example being "vehicle" is a super-ordinate; "car" is a basic level and "racing car" is a sub-ordinate [24]. Concepts are valuable, as they give us an effective way of representing our knowledge of the world and the object in it.

Having established what concepts are and how they can be organised, the final question is "what do concepts mean". Firstly, a concept's meaning can depend on its connection to other concepts in memory and secondly, the perceptual processes and connections between the concept and the external world [25]. In other words, concepts with a system depend upon the other concepts in the system and have a perceptual basis. Exemplar Approach has become the preferred approach when dealing with very complex concepts [26] and was the approach taken within the study. In addition, a concept in the context of this study means a unit of knowledge made up of a number of elements which operate as the characteristics of the concept.

\section{What is Organisational Resilience?}

Organisational Resilience as a term is often used; however, it is often vague in its interpretation and hard to define [27-29]. Nevertheless, resilience may be defined as the "quality or fact of being able to recover quickly or easily from, or resist being affected by, a misfortune, shock, illness, etc.; robustness; adaptability" [30]. Pooley and Cohen [31] suggest that resilience is the potential to exhibit resourcefulness by using available internal and external recourses in response to different contextual and developmental challenges.

Resilience differs in its definition when being referred to in the various domains to which it is now aligned including individual, community, business or national. Resilience is becoming a major part of all Australian Government planning and strategy in the future $[1,13,32]$. When applied to organisations, the 
prevailing objective of most definitions is the organisations ability to survive. This survival approach is then sustained by a number of pillars, best described as components. These components include prevention, protection, preparedness, mitigation, response and recovery. Nevertheless, the key to successful resilience appears to be an organisations ability to maintain adaptive, proactive and reactive strategies to deal with threats and risks [33].

Resilience, in academic terms, has its origin in fields of psychology and child behaviour [34, 35] and has been documented in social and ecological literature [36]. It is only recently that it began to appear in business literature [37, 38]. Resilience is a fundamental quality of individuals, groups, organisations, and systems as a whole to respond productively to significant change that disrupts the expected pattern of events without engaging in an extended period of regressive behaviour [39]. Resilient people deal with traumatic events in life and display hardiness, an ability to overcome difficulty and recover to continue with their lives [40-43].

\section{Resilient organisations}

Resilient organisations are much like resilient people in how they deal and survive unpredicted shocks like the recent Christchurch earthquake and Queensland's floods, and in some instances organisations can actually prosper. Resilience, in organisations, will be an imperative in the 21 st century as the occurrence of unforeseen and increase in unplanned low probability high impact events increases, as revealed during the 2009 iJet survey into organisational resilience capacities [7]. So what are resilient organisations?

"In terms of its organisational resilience and flexibility, its structure and communications, al-Qaeda is like a successful, smart company" [44]. Al-Qaeda's strength and resilience can be attributed to a clear message; a firm purpose; a charismatic leader; and no fear of delegating. Al-Qaeda has adopted a flatter linear organisational structure: Bin Laden is very good at issuing orders and making sure they were followed, while also setting clear goals and aims for the organisation. A key indicator of al-Qaeda's success lies in the organisation's ability to continue "to recruit, to mobilize .... fighters, supporters and sympathisers .... despite the punishment meted out to al-Qaeda ...., it still remains a potent terrorist threat" [44]. Hoffman credits the organisation's (alQaeda) resilience to its ability to change direction slightly so that it can survive.

Traditional resilience has been viewed as those qualities that enable an individual, community or organisation to cope with, adapt to and recover from a disaster event [45-48]. Organisational resilience remains theoretical and methods for achieving improved resilience at both operational and strategic levels within business still challenge both academics and practitioners [49].

Larger businesses are often essential to national economies, as is evidenced that more than 85 percent of the critical infrastructure in Western countries is owned and/or operated by the private sector [50]. Events or incidents that occur in one corner of the globe can have devastating effects across the entire globe; clearly proven when subprime mortgages in the United States failed in 2008, and 
world stock markets lost more than \$US17 trillion in the first 10 months of that year [51]. These types of events have highlighted the need for organisations to become more innovative or adaptive in their attitude to proactive strategies, thus ensuring more effective prevention, enhanced protection, increased preparedness, effective mitigation, increased response capacity and streamlined recovery processes.

It can be argued that traditional risk management systems and solutions are insufficient to handle today's expanded spectrum of market and business risk, including probabilistic risks and those that lead to community outrage. As the rate of change in the market accelerates, companies require an adaptive risk management approach that both responds to and anticipates business shifts. Organisational Resilience is based on an expanded view of risk - one that focuses on value and therefore encompasses not only traditional risks financial, natural hazard, physical security, legal compliance - but also risks related to innovation, intellectual property, partnerships and company culture. Organisational Resilience marries risk assessment, information reporting and governance processes with strategic and business planning to create an organisation-wide early warning capability that is embedded in the day-today operations and culture of the organisation [52].

Australia has begun considering how critical infrastructure protection can evolve into the next generation, using such an approach as resilience. Resilience is neither a plan nor a checklist. The capacity for resilience is found in an organisation's culture, attitudes and values. A truly resilient nation places equal emphasis on preparedness, protection, response and recovery so that it can withstand disruptive events that it knows are inevitable irrespective of their origin [29]. What may be clear from the resilience literature is that the field is dominated by specialists in varying domains, who have grasped and are moving forward in developing the philosophy. Resilience has become a widely used term by consultants, managers, bureaucrats and politicians, resulting in a catch-all terminology developing from efforts to encapsulate a complex multidimensional and multifunctional concept under a single banner. This approach has resulted in some re-badge ideas and claims of processes, management systems, computer software and measurement tools that will all create resilience [27].

Resilience is a common capacity possessed by individuals, groups or a community that allows them to prevent, minimise or prevail in the face of adversity. Resilience is often developed in expectation of foreseeable hardship. In centuries past, major disasters occurring in one country had minimal or no effects or impacts on other countries. Today, however, organisations transcend the globe and function across multiple countries. Resilience capacity is a multidisciplinary quality that allows an organisation to successfully withstand, respond to and potentially capitalise on disrupting events [37, 38, 53, 54]. It provides an underpinning of insight, adaptability, and robustness that enables an organisation to bounce back and create new ways to thrive when faced with uncertainty and adversity arising from a discontinuous jolt within its environmental. Resilience capacity is embodied in organisational routines and processes by which an organisation continually prepares itself, to act decisively 
and move forward, and establishes a culture of diversity and adjustable integration that empowers it to overcome the potentially incapacitating consequences of a disruptive shock [53].

\section{Identifying the essential concepts Organisational Resilience}

The primary outcome of this article is to develop and articulate an authoritative summarisation of Organisational Resilience, delivering a comprehensive set of the essential concepts that must be present to make an organisation resilient. This set will be supported by a detailed explanation of how those essential concepts benefit organisations in their quest to achieve their objectives. Such a combination will allow organisations to focus their efforts on a sustainable and progressive course of achieving "Organisational Resilience". It is argued that "Organisational Resilience" is in fact an outcome delivered by a number of functional processes, rather than a "management system". Resilience within an organisation is multi-faceted and heterogeneous. "Resilience refers to a capacity for continuous reconstruction. It requires innovation with respect to those organizational values, processes, and behaviours that systematically favour perpetuation over innovation" [37].

Currently the essential concepts of Organisational Resilience are not clearly understood. What is certain is that Organisational Resilience encompasses an organisation in its entirety and as such, there are numerous contributors across the organisation at both a tactical and strategic level. Having identified the extent of Organisational Resilience, properties that may be accepted as resilient characteristics can be put forward including interdependencies; security management; risk identification; leadership; situational awareness; information security management; risk assessment; communication; crisis management; risk treatment; corporate governance; risk avoidance; culture; values; emergency management; risk transfer; disaster recovery; business continuity and risk management.

Organisational Resilience is achieved through effective corporate governance and risk management, and is the new assurance process for promoting business success [55]. ASIS International promotes Organisational Resilience as security, preparedness and continuity management systems [3]. The Australian Government views resilience as neither a plan nor a checklist, but rather a capacity [29]. Sheffi in his "Building a Resilient Organisation" [50] promotes a supply chain interpretation of Organisational Resilience through building redundancy and flexibility. These varied approaches support the need for future study to more clearly understand and articulate the concepts of Organisational Resilience.

\section{Further study}

Continuing research needs to focus on the areas outside of the crisis, security and recovery fields, and look more closely at the ongoing cultural and developmental elements of Organisational Resilience. These elements are concentrated in and 
around the fields of organisational ethos; situational awareness, keystone vulnerability management and adaptive capacity [56]. These areas are significant to an organisations ability to not only bounce back but to spring forward from adversity.

\section{Conclusion}

Organisational resilience is currently being used extensively, but the term lacks definition, could be considered multi-disciplined, has diverse strategies and tactics and requires a diversity of skills and knowledge. The resilience domain is still developing; however, early embodiments of organisational resilience appear to be rebranding business continuity management strategies, security management and other, put together as a 'resilience processes' or 'resilience systems'. Nevertheless, this article argues that such an approach is inappropriate.

It is argued that Organisational Resilience is both a top-down and bottom-up process. Top-down considers the organisations' culture, values and leadership. Bottom-up may be delivered by a number of functional processes such as risk management, governance, interdependencies, security management, situational awareness and business continuity. However, validation of these elements is required and is currently underway in a current in-progress study where essential concepts will be extracted from international standards across many applied domains, tabulated and validated through a four-phased Grounded theory study.

\section{References}

[1] Department of Prime Minister, National Security Science and Innovation Strategy, P.M.a. Cabinet, Editor. Commonwealth of Australia: Canberra. 2009.

[2] Braes, B. and D. Brooks, Organisational Resilience: A propositional Study to understand and indetify the essential concepts. Proceedings 3rd Australian Security and Intelligence Conference, p. 14-22. 2010.

[3] ASIS, ASIS SPC. 1-2009 Security, preparedness and continuity management systems. ASIS International: Alexandria, Virginia. 2009.

[4] Cabinet Office, Dealing with Disaster. Brodie: Liverpool. 2003.

[5] Cabinet Office, Improving the resilience of Critical Infrastructure to Disruption from Natural Disaster. Crown: London. 2010.

[6] Hinrichs, G., Enactment, sensemaking and social agreement: An interpretive model of implementing high performance work systems, in Midwest Academy of Management. 2002: Lisle, Illinois. p. 219.

[7] iJet International Inc., 2009 Business Resilience Survey Results, in IJet Intelligent Risk Systems. Jjet: Annapolis. p. 4. 2009.

[8] Luthar, S.S., D. Cicchetti, and B. Becker, The construct of resilience: a critical evaluation and guidelines for future work. Child Dev, 71(3): p. 54362. 2000 . 
[9] Dansk, DS-3001:2009 Organisatorisk robusthed - Ledelsessystem for sikkerhed, beredskab og forretningsvidereførelse - Krav og vejledning. Danish Standards: Charlottenlund, Denmark. 2009.

[10] Normalisatie, N., Maatschappelijke veiligheid - Managements stemen voor veiligheid. voorbereiding op incidenten en continuiteit - Eisen en aanbevelinfen voor het gebruik. Nederlands Normalisatie instituut: Delft, NL. 2010.

[11] ISO, ISO223xxx, Organizational Resilience Management Systems. 2009.

[12] Attorney General Department. Natural Disaster Resilience Program. Available from: http:/www.ema.gov.au/www/emaweb/emaweb.nsf/Page/ FundingandGrants_FundedPrograms_NaturalDisasterResilienceProgram. 2009

[13] Department of Prime Minister, Critical Infrastructure Resilience Strategy, A. General, Editor. Commonwealth of Australia: Canberra. 2010.

[14] Director General Developments Concepts and Doctrine, Operations In The UK: The Defence Contribution To Resilience, Defence, Editor. The Chiefs of Staff: London. 2007.

[15] Rowe, W., The Delphi technique as a forecasting tool: issues and analysis. International Journal of Forecasting, 15(4). 1999.

[16] Pidgeon, N.F. and K. Harwood, Handbook of Qualitative research: Methods for Psychology and the Social Sciences Grounded Theory: practical Implementation, ed. J.T.E. Richardson. Leicester: British Psychological Society, Brooks. 1996.

[17] Didkowsky, N., M. Ungar, and L. Liebenberg, Using visual methods to capture embedded processes of resilience for youth across cultures and contexts. J Can Acad Child Adolesc Psychiatry, 19(1): p. 12-8. 2010.

[18] Reisberg, D., Cognition: Exploring science of the mind. 2 ed. New York: W.W. Norton \& Company. 2001.

[19] Eysenck, M.W. and M.T. Keane, Cognitive psychology: A students handbook. New York: Psychology Press Ltd. 2005.

[20] Ullman, M.T., Contributions of memory circuits to language: the declarative/procedural model. Cognition, 92: p. 231-70. 2004.

[21] Borges, J.-L., Labyrinths. London: Penguin. 1964,

[22] Macnamara, J., Names of things: A study of human learning. 1982, Cambridge, MA: M.I.T. Press.

[23] Murphy, G.L., The big book of concepts. Cambridge, MA.: M.I.T. Press. 2002.

[24] Rosch, E., et al., Basic objects in natural categories. Cognitive Psychology, 8. 1976.

[25] Goldstone, R.L. and B.J. Rogosky, Using relations within conceptual systems to translate across conceptual systems. Cognition, 8(8): p. 295-320. 2002.

[26] Feldman, J., The simplicity principle in human concept learning. Current Directions in Psychological Science, 12. 2003. 
[27] Gibson, C.A. and M. Tarrant, $A$ 'conceptual models' approach to organisational resilience. The Australian Journal of Emergency Management, 25(2). 2010.

[28] KPMG, Living on the front line The resilient organisation, in http://www.kpmg.com.sg/publications/Advisory_LivingOnTheFrontline.pdf, K. LLP, Editor. March, KPMG: London. 2007.

[29] TISN, National Resilience Framework Workshop - The Outcomes, in National Resilience Framework Workshop, A.s.T.I.S.N.f.C. Infrastructure and P. (TISN), Editors. 2007, Attorney General Dept - Emergency Australia: Mount Macedon, Victoria, Australia.

[30] Oxford, Oxford English Dictionary. Oxford University Press: Oxford. 2010.

[31] Pooley, J.A. and L. Cohen, Resilience: A Definition in Context. Australian Community Psychologist, (November). 2010.

[32] Cork, S., ed. Brighter prospects: Enhancing the resilience of Australia. 2009, Australia 21: Canberra.

[33] Sutcliffe, K. and T.J. Vogus, eds. Organising for Resilience. BerretKoehler: San Francisco. 94-110. 2003.

[34] Coutu, D., How Resilience Works. Harvard Business Review, p. 46-55. 2002.

[35] Reinmoeller, P. and N. Van Baardwijk, The Link Between Diversity and Resilience. MIT Sloan Management Review, Summer 2005: p. 61-65. 2005.

[36] Walker, B. and D. Salt, Resilience Thinking; sustaining ecosystems and people in a changing world. Washington D.C.: Island Press. 2006.

[37] Hamel, G. and L. Valikangas, The quest for resilience. Harv Bus Rev, 81(9): p. 52-63, 131. 2003.

[38] Hamel, G. and L. Valikangas, The Quest For Resilience. Harvard Business Review, p. 52-63. 2003.

[39] Horne III, J. and J. Orr, Assessing behaviours that create resilient organisations. Employment Relations Today, Winter: p. 29. 1998.

[40] Kobasa, S.C., Commitment and coping with stress resistance among lawyers. Journal of Personality \& Social Psychology, 24(4): p. 707-717. 1982.

[41] Kobasa, S.C., S.R. Maddi, and S. Kahn, Hardiness and Health: A prospective study. Journal of Personality \& Social Psychology, 21: p. 168177. 1982.

[42] Westman, M., The relationship between stress and performance: The moderating effect of hardiness. Human Performance, 3(3): p. 141-155. 1990.

[43] Baron, L., et al., Stress resilience, locus of control, and religion in children of Holocaust victims. J Psychol, 130(5): p. 513-25. 1996.

[44] Hoffman, B., What we can learn from terrorist. Global Horizons, 2. 2004.

[45] Buckle, P., G. Mars, and S. Smile, New approaches to assessing vulnerability and resilience. Australian Journal of Emergency Management, 12(2): p. 8-15. 2000. 
[46] Horne, J.F.I., A New Direction; The Coming of Age of Organisational Resilience. Business Forum, 22(2/3): p. 24-28. 1997.

[47] Pelling, M. and J.I. Uitto, Small Island Developing States; Natural Disaster Vulnerability and Global Change. Environmental Hazards, 3: p. 49-62. 2001.

[48] Riolli, L. and Savicki, Information System Organisational Resilience. Omega The International Journal of Management Science, 31: p. 227-233. 2003.

[49] Klein, R.J.T., R.J. Nicholls, and F. Thomalla, Resilience to Natural Hazards: how use is this concept. Environmental Hazards, 5: p. 35-45. 2003.

[50] Sheffi, Y., Building Resilient Organisation. The Bridge, 37(1): p. 1. 2007.

[51] Silverblatt, H., World By Numbers, S. Poors, Editor. 2008, McGraw Hill: New York.

[52] Booz Allen Hamilton Inc and Weil Gotshal \& Manges LLP, Redefining the Corporate Governance Agenda, M.B. Paul Kocourek, Editor. New York. 2004.

[53] Lengnick-Hall, M.L. and T.E. Beck, Adaptive fit versus robust transformation: How organizations respond to environmental change. Journal of Management. 31(5): p. 738-757. 2005.

[54] McGann, J., Organisational Effectiveness: Changing Concepts for Changing Environments:: Human Resource Planning, 27(1): p. 42-50. 2004.

[55] Dahms, T., Resilience and risk management. The Australian Journal of Emergency Management, 25(2). 2010.

[56] Seville. E, Resilience: Great concept... but what does it mean? in US Council on Competitiveness Workshop, Risk and Resilience. Wilmington, USA. 2008: 